\title{
Study on Aseismic Characteristics of Tibetan Ancient Timber Structure
}

\author{
Juan Wang, Junxiao He, Na Yang, and Qingshan Yang \\ Beijing's Key Laboratory of Structural Wind Engineering and Urban Wind Environment, School of Civil Engineering, \\ Beijing Jiaotong University, Beijing 100044, China \\ Correspondence should be addressed to Juan Wang; juanwang@bjtu.edu.cn
}

Received 8 October 2016; Accepted 14 February 2017; Published 16 March 2017

Academic Editor: Gianluca Cicala

Copyright (C) 2017 Juan Wang et al. This is an open access article distributed under the Creative Commons Attribution License, which permits unrestricted use, distribution, and reproduction in any medium, provided the original work is properly cited.

\begin{abstract}
Tibetan ancient timber structure has great historical, cultural, artistic, and scientific values. The structural configuration of members such as wall, roof, slab, and timber skeleton with semirigid joints is studied in this paper based on field survey results. The aseismic characteristics of Tibetan ancient timber structure have been summarized and introduced. One of the unique features of the Tibetan ancient timber structure is its special beam-column joint which has a semirigid behavior. Numerical simulations of a typical 3-storey structural unit in the Potala Palace are studied. The acceleration responses of the structure under the action of El-Centro seismic waves are studied. Results show that the arrangement of the joints is helpful for seismic resistance of the structure. Most Tibetan ancient timber structures are suffering from different types of damage to certain extent which is vulnerable to seismic actions. Typical damage problems of the structural components are summarized and the main causes of this damage are analyzed. Different rehabilitation methods that can be implemented are discussed, providing references for maintenance of the structures.
\end{abstract}

\section{Introduction}

Timber structure can be frequently found in historic buildings in Tibet. As a treasure of architectural heritage in China, Tibetan ancient timber structure has its own distinguished features due to the special natural environment, history, and culture in Tibet. Pictures of typical Tibetan ancient timber structure are shown in Figure 1.

Study of Chinese ancient architecture began in the 1930s. Liang and other architects published a lot of field investigation reports which have big influences to later studies on the Chinese ancient structures [1]. It is however, not until 1990s, that some scientists began to employ structural analysis in their research on ancient timber structures. Ma studied the building technologies of ancient Chinese timber structures [2]. Wang's research focused on the distribution and transmission of vertical loads in timber structural members [3].

Due to an urgent need to protect the historic buildings, many rehabilitation projects on existing ancient timber buildings have been carried out. Scholars have done exploratory tests and studies to provide references for the maintenance and protection of ancient timber structure. Systematic studies on the structural mechanics of ancient architectures have been carried out at Xian Jiaotong University since 1982. Structural mechanics, computational approaches, and modern experimental methods were firstly brought into the structural analysis of ancient timber structures [4]. Fang et al. conducted on-site measurements and model tests on the front tower over the North Gate of the Xi'an City Wall. The first several natural frequencies of the structure were found. Damping ratio and the hysteresis curves were obtained. A semirigid Finite Element Model (FEM) is developed to simulate the behavior of Dou Gong (corbel brackets) and MortiseTenon joints. A three-dimensional FEM was established to study the dynamic characteristics of the structure. The FEM program SAFATS was developed to conduct dynamic and earthquake response analysis for this kind of timber structure [5]. Research group of Xi'an University of Architecture and Technology have taken a series of studies and tests on ancient timber structure since 1999. Xue et al. analyzed the earthquake responses on historic palace timber building, and they pointed out that the structures possessed good aseismic resisting behaviors [6]. The research group conducted static and low cyclic loading tests of structural components, such as Dou Gong and Mortise-Tenon joint and shaking table test 


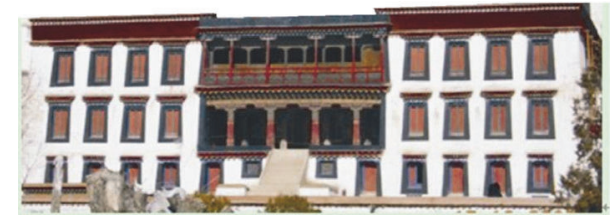

(a) Building facade

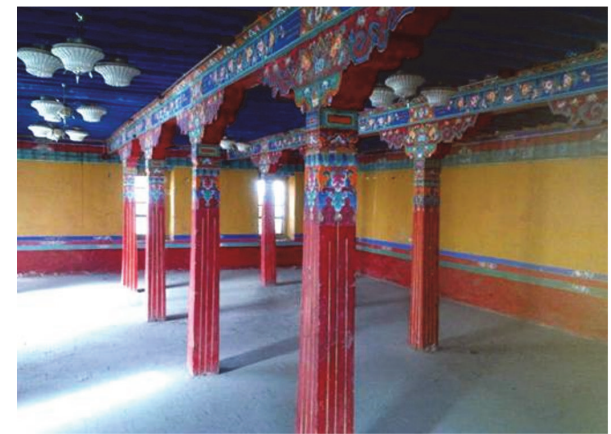

(b) Inside the building

Figure 1: Pictures of typical Tibetan ancient timber structure.

of a hall to study the aseismic mechanism of ancient timber structure [7-10].

The aforementioned literatures are mostly on traditional ancient timber structure. For Tibetan ancient buildings, most studies were focused on the historical and artistic features of the building and only a few were on the structural features. Jiang and Gasu are involved in the first large-scale maintenance project of the Potala Palace, and they studied the failure modes of the structure and its components with mechanical characteristics of the structure [11]. Chen presented the material and construction details of Tibetan architectures [12]. Guo and Yang conducted field test on a typical Tibetan ancient structure instrumented with displacement and acceleration transducers to study the effect due to crowd walking and running [13]. The measured data is then used to analyze the dynamic property such as fundamental frequency and damping ratio of the test structure. The acceleration time histories were used to evaluate the vibration serviceability of the floor slab. Yan analyzed the static properties of the beam-column through tests and numerical simulations [14]. The moment-rotation relation of the joint is derived from the test results. Yang et al. studied the timber material of Tibetan ancient timber structure. The main mechanical properties of three kinds of timber including the old Tibetan Populus cathayana, new Tibetan Populus cathayana, and new Tibetan Pine were obtained by tests. The principles and assumptions made in the determination of their strengths and timedependent laws on the design strength of timber in ancient Tibetan structures were discussed [15].

In this paper, the structural configuration of Tibetan ancient timber structure with connections, such as the column base, chock block, short stick and mortise-tenon connection, is studied based on a large number of field survey results. The differences of construction and force flow between Han-style and Tibetan buildings are introduced. The aseismic characteristics of Tibetan ancient timber structure have been introduced. Semirigid beam-column joint, which is one of the most important features of Tibetan ancient timber structure, influences significantly the global behavior of the structural system. Numerical simulations of a typical 3-storey structural unit in Potala Palace are studied. The acceleration responses of the structure under the action of El-Centro seismic waves are studied. Most Tibetan ancient timber structures are suffering from different degrees of structural damage which are weakness to the seismic resistance. Typical damage problems of the structural components are summarized and the main causes of this damage are analyzed. Different rehabilitation methods that can serve as references for maintenance of the Tibetan ancient timber structure are also discussed.

\section{Structural Configuration}

Figures 2 and 3 show the two kinds of typical Han-style timber structures with post and lintel skeletons. Timber frame with laminated beams and columns shown in Figure 2 is mainly in north of China. The timber skeleton of this kind of structure consists of posts and cross beams rising toward the ridge in diminishing lengths. The purlins-horizontal members that support the rafters are positioned along the stepped shoulders of the skeleton. The rafters are short, stretching down only from purlin to purlin [1]. Figure 3 is the timber frame with column and ties usually used in south of China [16]. The main feature of this kind of structure is that the purlins are supported directly by columns. The cross tie connecting the columns is called Chuan, only having the cross link function.

Typical Tibetan timber structure shown in Figure 4 is quite different from Han-style ancient timber structures. For either kind of Han-style timber structure, timber skeleton is the main load bearing system and the wall only has an enclosure function. In Tibetan architecture, wall and timber frame are both load bearing components as shown in Figure 4(a) [17] and Figure 4(b). In a space separated by walls, the vertical row frame series composed of beams and columns support rafters at close spacing and upper plat roof. Figure 4(c) shows the typical frame of Tibetan ancient timber structure. The components such as beam, cap block, chock block, and column are connected with each other by short sticks. Chock blocks are used at the top of column for supporting the beam.

\section{Aseismic Characteristics of Tibetan Ancient Timber Structure}

Typical Han-style timber structures with mortise and tenon joints connecting structural components can be defined as a kind of flexible structure. The rotation and slip of joints can 


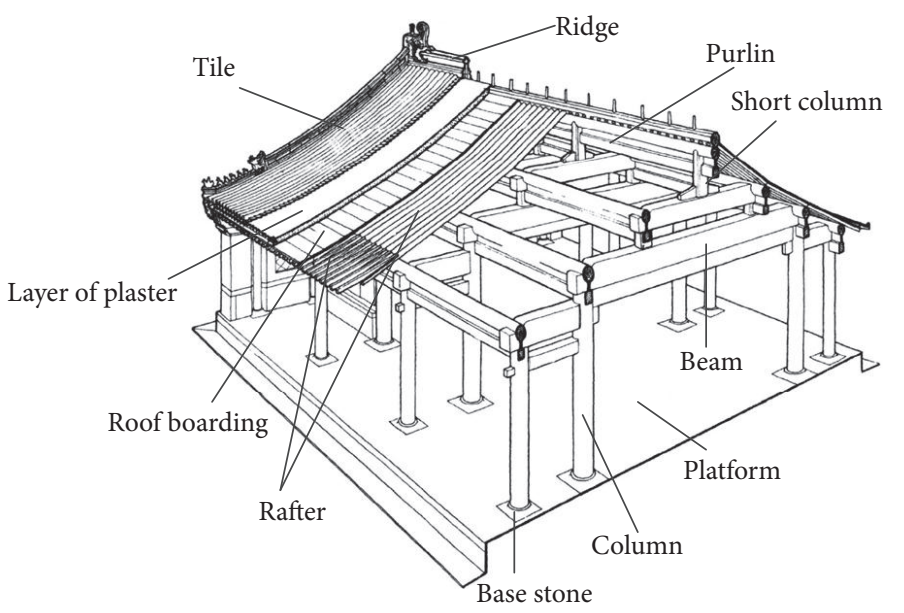

(a) 3D view of timber frame with laminated beams and columns

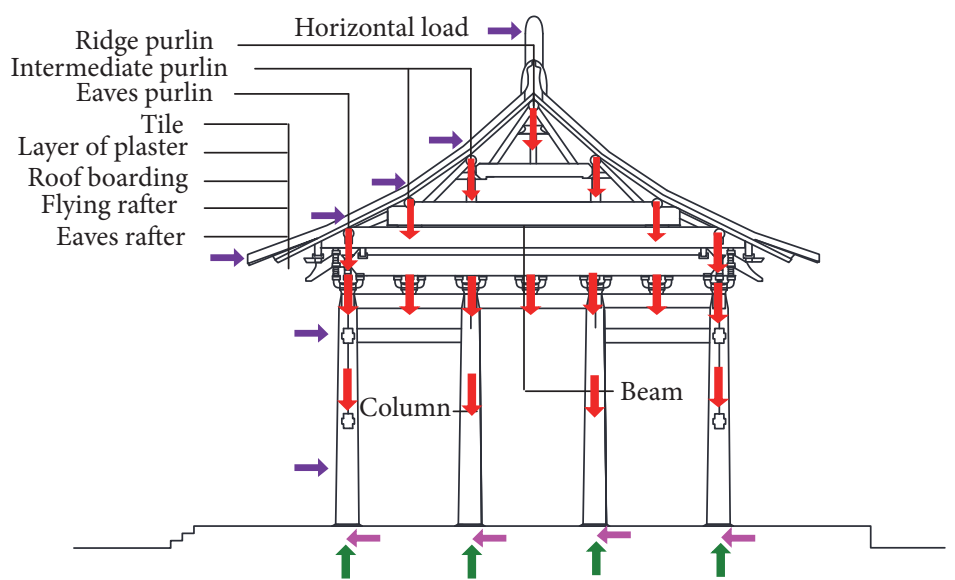

(b) Cross section of timber frame with laminated beams and columns

FIGURE 2: Timber frame with laminated beams and columns.

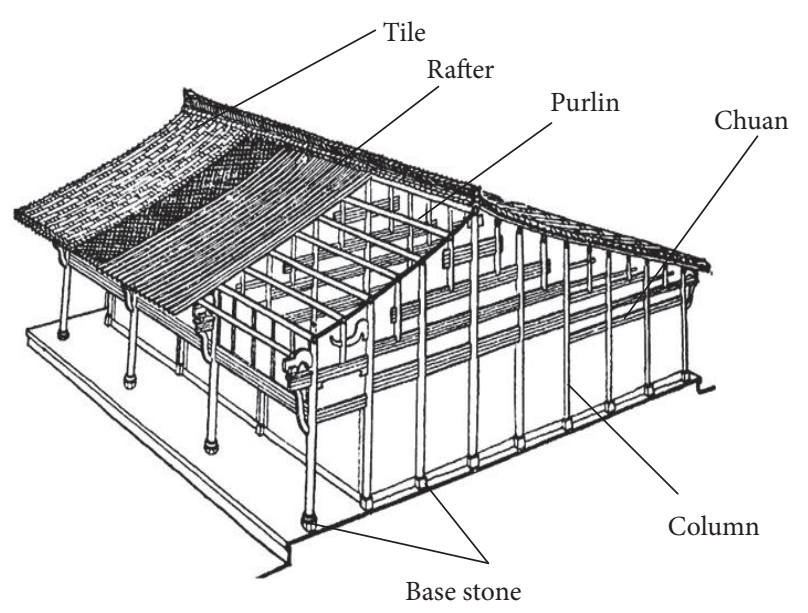

(a) 3D view of timber frame with columns and ties

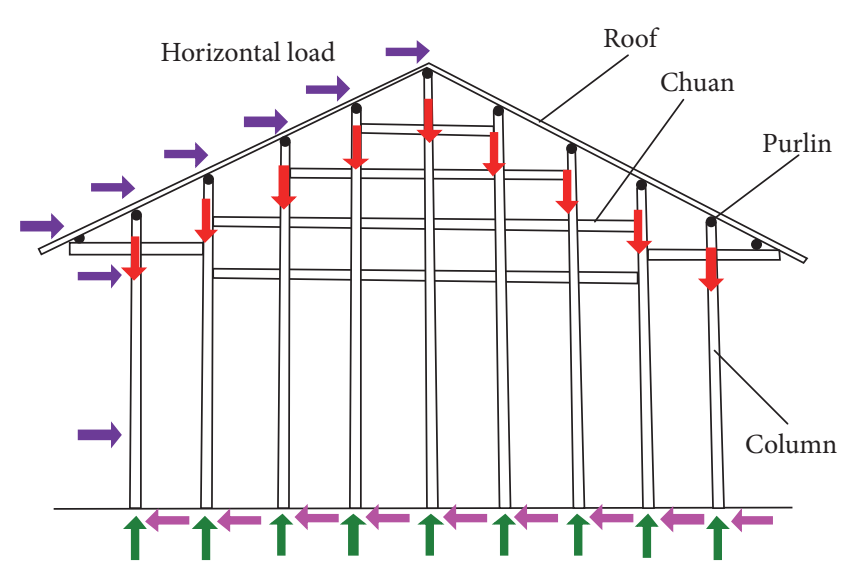

(b) Cross section of timber frame with columns and ties

Figure 3: Timber frame with columns and ties. 


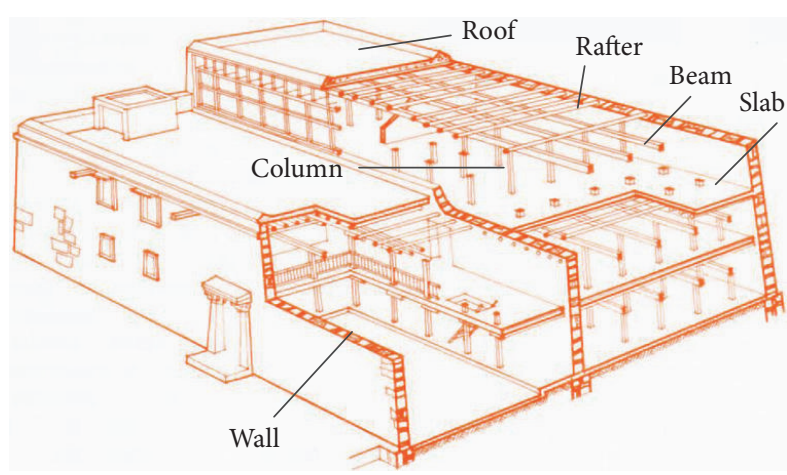

(a) $3 \mathrm{D}$ view of Tibetan timber structure

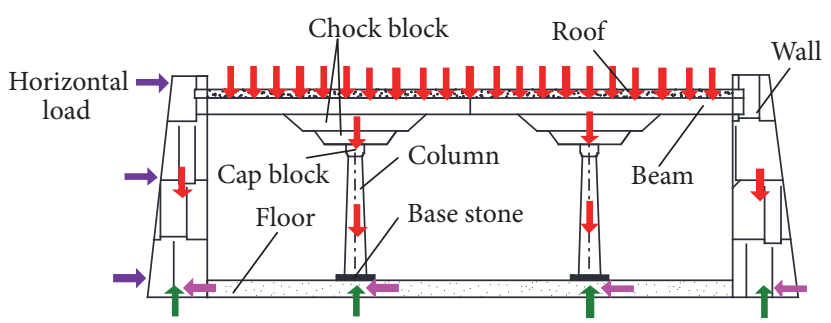

(b) Cross section of Tibetan timber structure

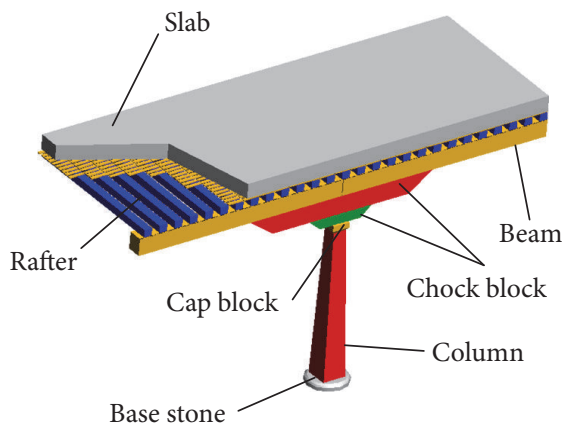

(c) Frame of Tibetan timber structure

FIgURE 4: Typical Tibetan timber structure.

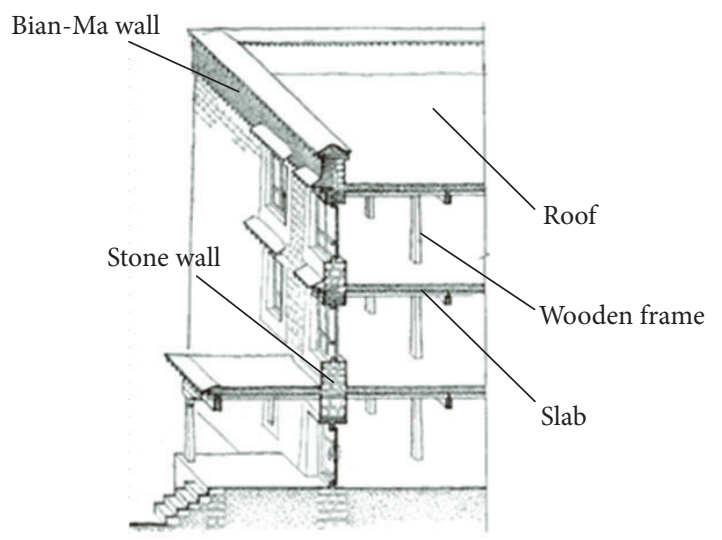

FIGURE 5: Rigid-flexible combination structure.

dissipate a large amount of energy when taking up seismic load. For Tibetan timber structure, it can be defined as a kind of rigid-flexible combination structure as shown in Figure 5 [12]. Timber frame together with masonry wall and strong roof not only ensure the bearing capacity of the structure, but also make the structure have certain ductility under earthquake.

Figure 6 shows the masonry outer wall with inward tilt [18]. It makes the gravity center of the wall lower to let the wall be more stable. Bian-Ma wall shown in Figure 7 is usually used at the top of the outer wall. It is made of willows fixed by pieces of wood, reducing the weight of the upper wall [12].
Bian-Ma wall is painted in red color, decorating the facade of the building.

Figures 8(a) and 8(b) show the construction layers of roof and slab, respectively. Slab can also be constructed by the same layers of roof, but with thinner Aga soil. The strong roof and slabs let the overall stiffness of the structure be strengthened.

It is found in Figure 9(a) that, similar to outer wall, columns are usually with inward tilt, making the timber skeleton more stable. The column base is not inserted into but is resting directly on top of a stone base as shown in Figure 9(b).

Semirigid beam-column joint is one of the most important features of Tibetan ancient timber structure. The components such as beam, cap block, chock block, and column are connected with each other by short sticks as shown in Figure 10(a). The short sticks not only have the role of geometric positioning, but also can improve the shear stiffness of the joint. Under shear load, the deformation of the joint components will experience four stages, which are slip, elastic, elastic-plastic, and plastic stages. Yielding failure of the short sticks will occur when the relative slippage of the joint components is too big.

There are strict limits on the size and proportions of the joint components. The width of the cap block is slightly bigger than the width of the top of column as shown in Figure 10(b). Two chock blocks are layered above the cap block and the length of the lower one is shorter than the upper one as shown in Figure 10(c). The width of the beam above them is slightly bigger than the upper chock block. The two 


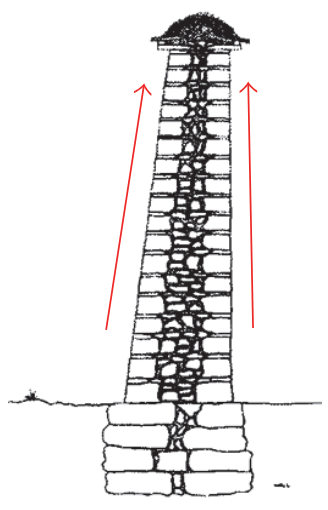

(a) Diagrammatic sketch of the wall

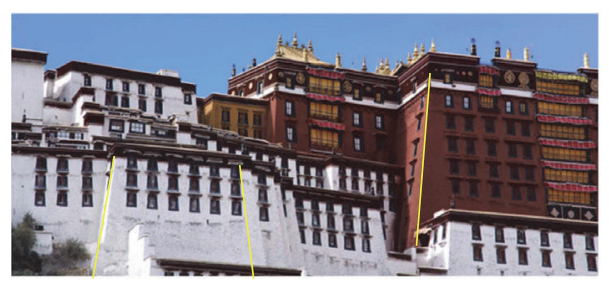

(b) Picture of the wall

FIGURE 6: Outer wall with inward tilt.

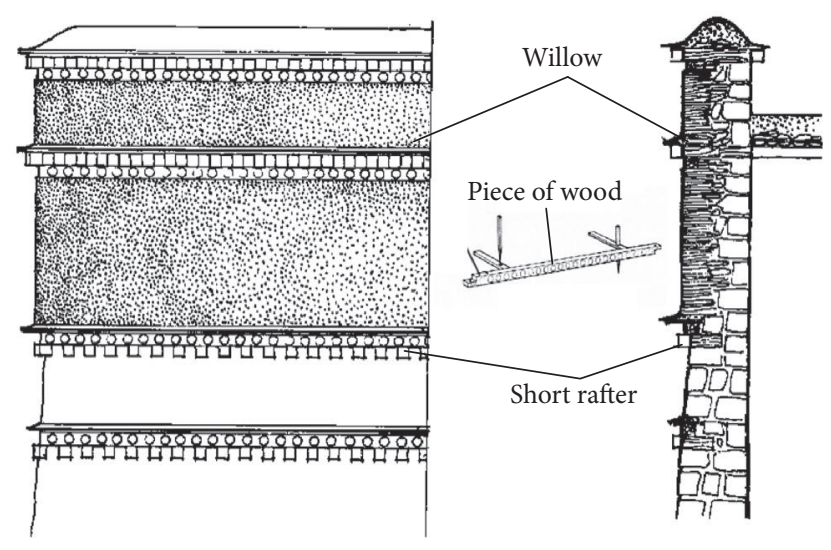

(a) Diagrammatic sketch of the wall

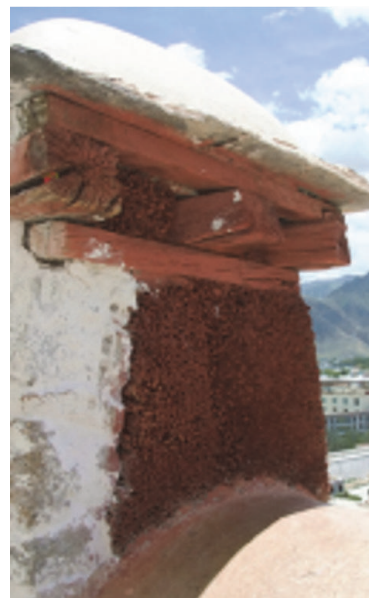

(b) Picture of the wall

Figure 7: Bian-Ma wall.
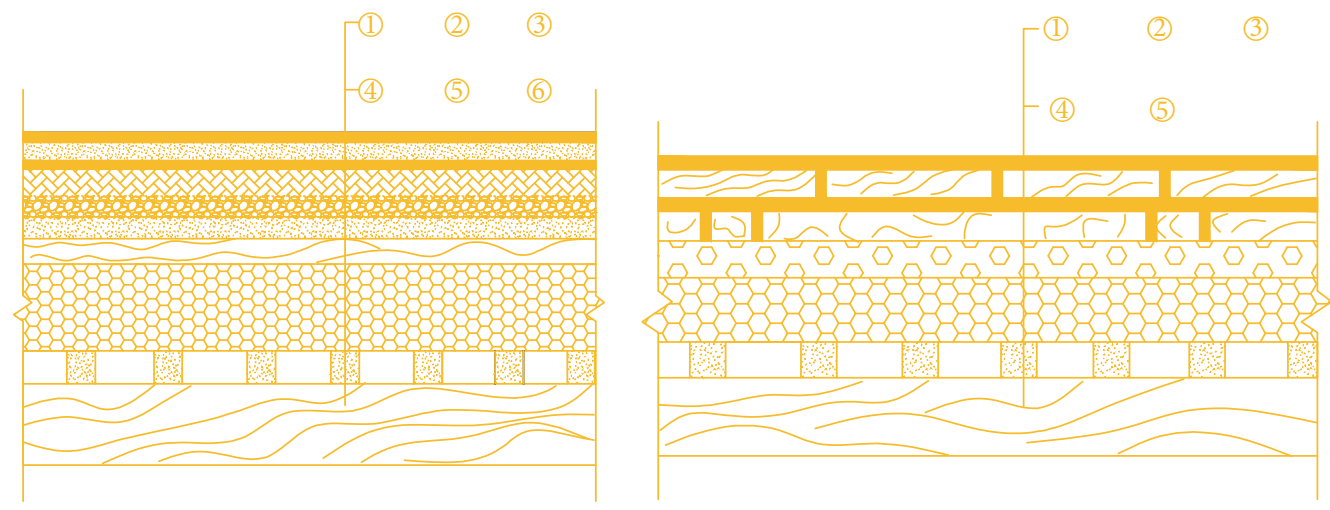
(1) Aga soil
(4) Dry stick
(2) Sand and pebble
(5) Rafter
(3) Board
(6) Beam

(1) Wood floor

(4) Rafter

(2) Wooden grid

(5) Beam

(3) Dry stick

(a) Construction layers of roof

(b) Construction layers of slab

FIgURE 8: Construction layers of roof and slab. 


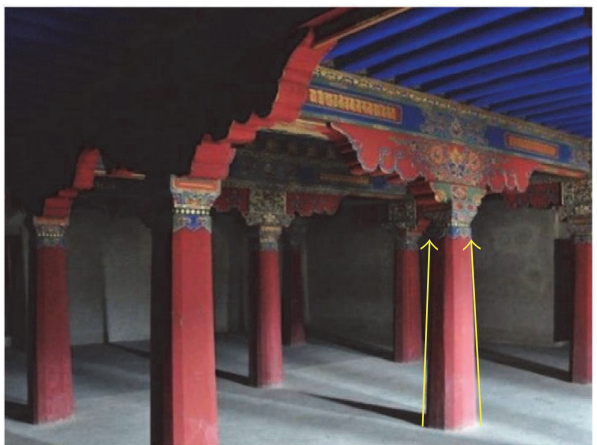

(a) Column with inward tilt

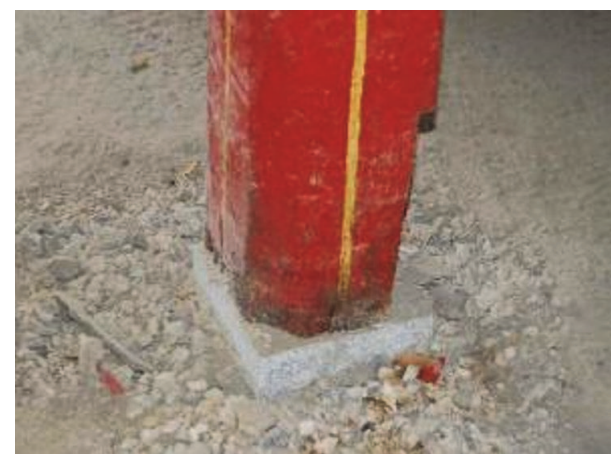

(b) Base stone of the column

FIgURE 9: Column of the timber skeleton.

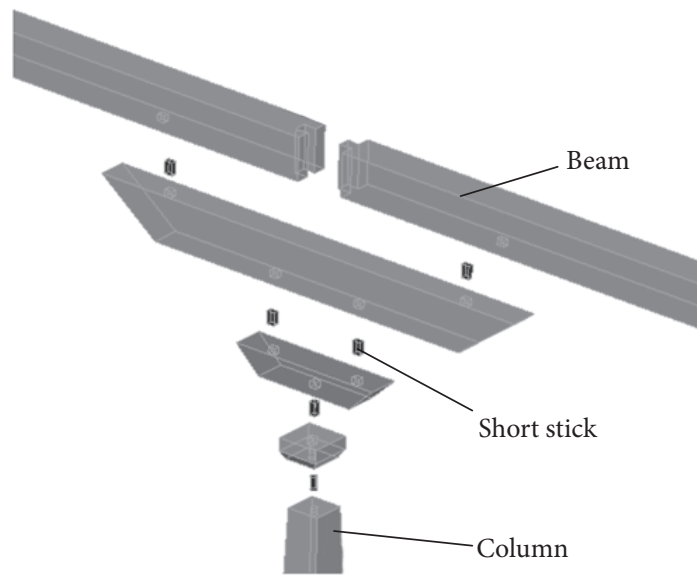

(a) Inner connections between joint components

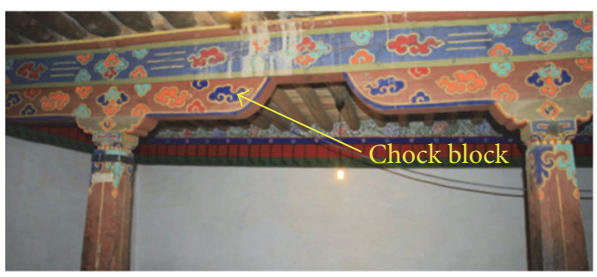

(c) Chock block

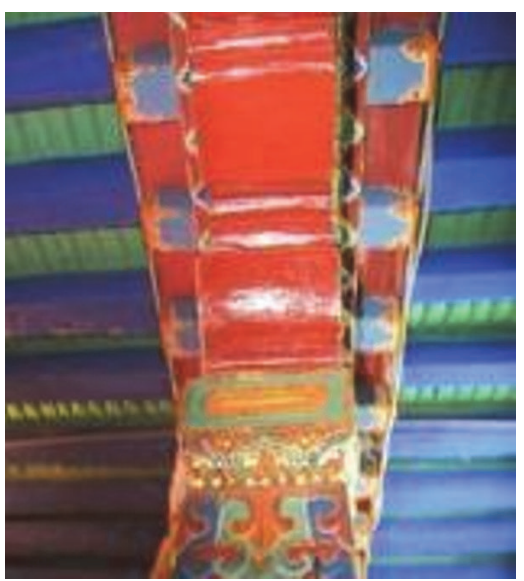

(b) Joint components

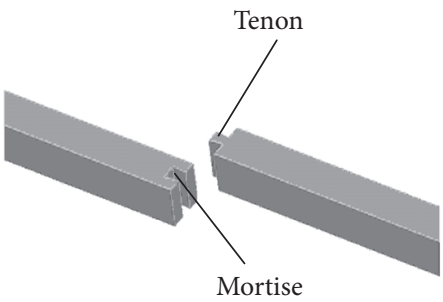

(d) Mortise and Tenon connection

FIgURE 10: Semirigid beam-column joint.

chock blocks improve the shear and flexural capacity of the joint.

The mortise and tenon connection is a semirigid connection, and it is used between beams as shown in Figure 10(d). Usually the mortise cannot completely fit the tenon due to manufacturing errors. At the beginning of loading, the joint can be considered as a hinge joint. Mortise and tenon grip each other tightly as the load increases. The joint is no longer hinged if slippage exists between mortise and tenon. If the load continues to increase, the joint will finally reach its limit state with the tenon pulled out of the mortise. Under the action of earthquake, energy dissipation of the joint occurs by friction and compression between mortise and tenon, such that the earthquake responses of the structure can be reduced.

\section{Characteristics of Semirigid Beam-Column Joint}

4.1. Numerical Simulations. The FEM of a typical 3-storey structural unit in the Potala Palace is developed using the ANSYS software package. The geometric size of the building and its members is measured on site. Figure 11(a) shows a picture of the structure. Figures 11(b) and 11(c) are the plan and elevation of the structure, respectively. The FEM 


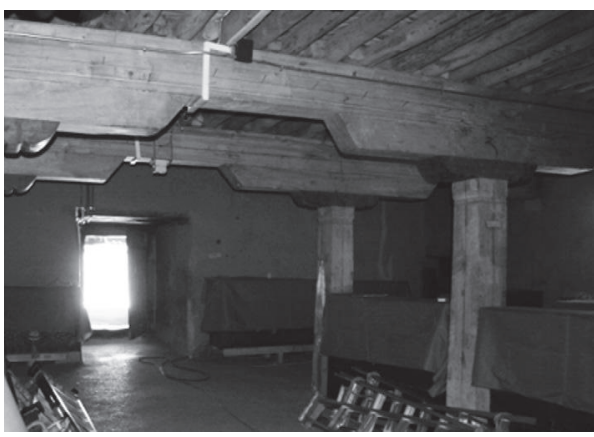

(a) A picture of the building

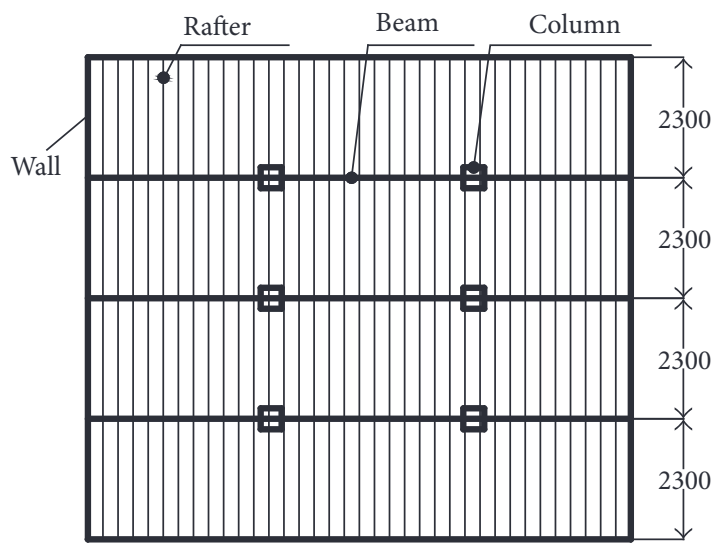

(c) Building plan

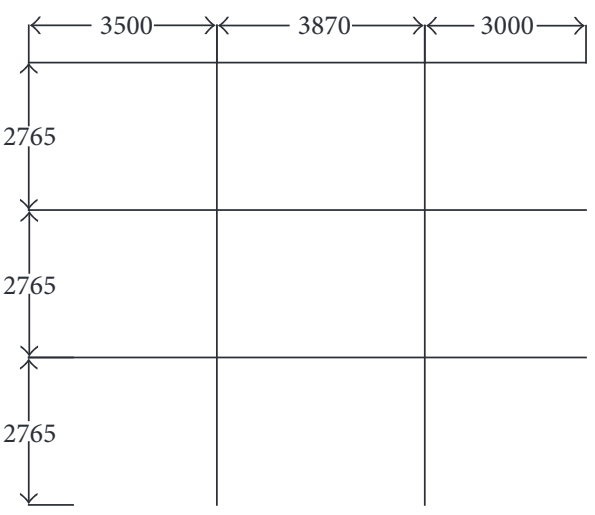

(b) Building elevation

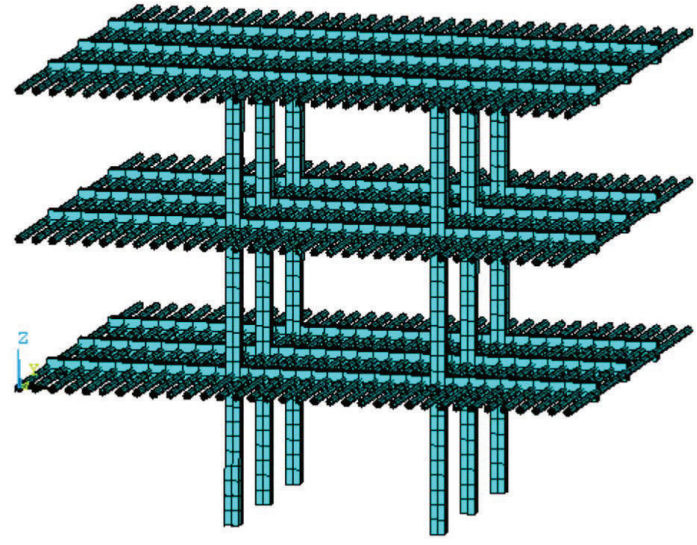

(d) FEM of the building

FIGURE 11: Information of the FEM.

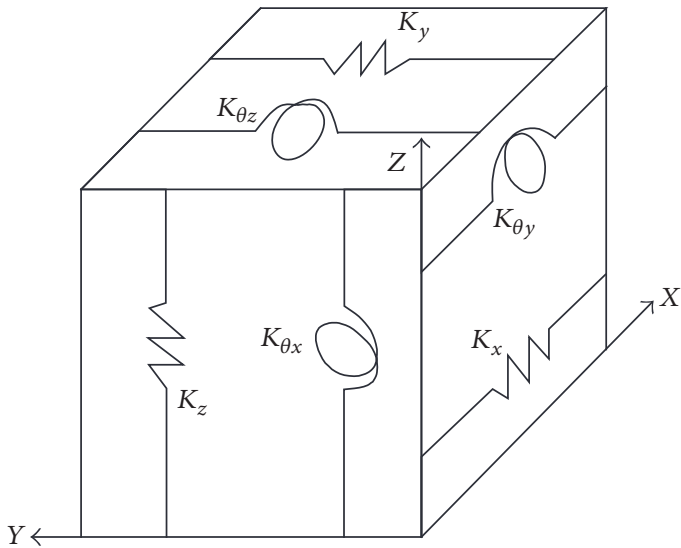

FIgURe 12: Spring element.

as shown in Figure 11(d) consists of three kinds of structural components which are beam, column, and rafter. The crosssectional dimensions of beam are $b=0.22 \mathrm{~m}$ and $h=0.35 \mathrm{~m}$. The cross section of column is square with $0.27 \mathrm{~m}$ edges. The rafter has circular cross section with $0.07 \mathrm{~m}$ radius.

The beams, columns, and rafters are all simulated as beam element with six degrees of freedom at each node.
As shown in Figure 12, the beam-column joint is simulated by an element composed of 6 separate springs [19]. The stiffness matrix for the element is defined in (1), where $k_{x}$, $k_{y}$, and $k_{z}$ represent the translational stiffness values in $x$, $y$, and $z$ directions, respectively, while $k_{\theta x}, k_{\theta y}$, and $k_{\theta z}$ represent the rotational stiffness around $x, y$, and $z$-axis, respectively. 


$$
k_{e}=\left[\begin{array}{cccccccccccc}
k_{x} & 0 & 0 & 0 & 0 & 0 & -k_{x} & 0 & 0 & 0 & 0 & 0 \\
0 & k_{\theta x} & 0 & 0 & 0 & 0 & 0 & -k_{\theta x} & 0 & 0 & 0 & 0 \\
0 & 0 & k_{y} & 0 & 0 & 0 & 0 & 0 & -k_{y} & 0 & 0 & 0 \\
0 & 0 & 0 & k_{\theta y} & 0 & 0 & 0 & 0 & 0 & -k_{\theta y} & 0 & 0 \\
0 & 0 & 0 & 0 & k_{z} & 0 & 0 & 0 & 0 & 0 & -k_{z} & 0 \\
0 & 0 & 0 & 0 & 0 & k_{\theta z} & 0 & 0 & 0 & 0 & 0 & -k_{\theta z} \\
-k_{x} & 0 & 0 & 0 & 0 & 0 & k_{x} & 0 & 0 & 0 & 0 & 0 \\
0 & -k_{\theta x} & 0 & 0 & 0 & 0 & 0 & k_{\theta x} & 0 & 0 & 0 & 0 \\
0 & 0 & -k_{y} & 0 & 0 & 0 & 0 & 0 & k_{y} & 0 & 0 & 0 \\
0 & 0 & 0 & -k_{\theta y} & 0 & 0 & 0 & 0 & 0 & k_{\theta y} & 0 & 0 \\
0 & 0 & 0 & 0 & -k_{z} & 0 & 0 & 0 & 0 & 0 & k_{z} & 0 \\
0 & 0 & 0 & 0 & 0 & -k_{\theta z} & 0 & 0 & 0 & 0 & 0 & k_{\theta y}
\end{array}\right]
$$

The stiffness of the six springs is determined based on the numerical and experimental studies [20], where

$$
\begin{aligned}
k_{x} & =10^{10}, \\
k_{y} & =k_{z}=1.579 \times 10^{6}, \\
k_{\theta x} & =k_{\theta z}=9.266 \times 10^{6} .
\end{aligned}
$$

The stiffness of $k_{\theta y}$ is defined as a bilinear model shown in Figure 13 [14].

The FEM includes 2586 beam elements and 216 springs. The total element number and node number are 2802 and 3051, respectively. The wall in Tibetan ancient timber structure is very thick and it is made of big stone and soil. Since there is no information on the physical properties of the composition material of the wall, in the FEM the wall is assumed as support to the timber frame. Connection between the beam and wall is considered rigid with moment fixity because the beam end is inserted into the wall. As the rafter is considered to have rotational degrees of freedom, only translation in $x, y$, and $z$ directions have to be restrained. The slab and sticks are simulated as distributed masses on rafter.

The timber material used in the structure is Tibetan Cathay Poplar, and for their properties please refer to [21]. The mass density and elastic modulus of material are $418 \mathrm{~kg} / \mathrm{m}^{3}$ and $6.435 \mathrm{Gpa}$, respectively. The stress-strain behavior of timber is assumed to be bilinear. Poisson's ratio is 0.2 and the yield stress is $31.01 \mathrm{Mpa}$. Von Mises yield criterion is applied in the simulation.

4.2. Modal Analysis. The natural frequencies of the structure are obtained using the method of Block Lanczos. The fundamental frequency of the model with semirigid beam-column joints is $2.035 \mathrm{~Hz}$ which is quite close to the measured result $2.05 \mathrm{~Hz}$ [13]. It is proved that the FEM with semirigid joints is suitable for modeling the structure.
4.3. Earthquake Response Analysis. To study the aseismic characteristics of the semirigid beam-column joint of the Tibetan ancient timber structure, N-S El-Centro seismic waves are applied along the $x$-axis of the structure. The acceleration responses from arbitrarily selected points of the structure as shown in Figure 14 when under the N$\mathrm{S}$ El-Centro seismic waves with acceleration peak value 70 gal (small earthquakes) and 400 gal (large earthquakes) are studied. The FEM with rigid joints is taken as a reference to evaluate the dynamic and aseismic performance of the model with semirigid joints. In the FEM with rigid joints, the translational stiffness values $k_{x}, k_{y}$, and $k_{z}$ are set as $10^{15} \mathrm{~N} / \mathrm{m}$ and the rotational stiffness values $k_{\theta x}, k_{\theta y}$, and $k_{\theta z}$ are set as $10^{15} \mathrm{Nm} / \mathrm{rad}$.

Figures 15(a) and 15(b) are the acceleration responses of Node 2921 (column) and Node 2644 (beam) in the FEM with semirigid joints under El-Centro waves (Duration $10 \mathrm{~s}$, time interval $0.02 \mathrm{~s}$ ) with acceleration peak values $70 \mathrm{gal}$ and 400 gal, respectively. Node 2921 and Node 2644 have the same coordinates and are on two sides of a semirigid joint with 6 springs. The average of the absolute value of the acceleration response history is used as a measure for comparison of the two sets of acceleration responses. It can be found in Table 1 that the average values of Node 2921 are bigger than that of Node 2644. It is revealed that the semirigid beam-column connections are just like dampers that can reduce the earthquake responses by friction and extrusion.

Figures 15(c) and 15(d) show the acceleration responses of Node 2798 in the two FEMs under El-Centro waves with acceleration peak values 70 gal and 400 gal, respectively. It is noted that the peak acceleration responses of Node 2798 in the FEM with semirigid joints are lower than those in the FEM with rigid joints. Figures 15(e) and 15(f) are acceleration responses of Node 2920 in the two FEMs and the results are similar to Figures 15(c) and 15(d). It can be found in Table 1 that the average values of Node 2920 are bigger than that of 
TABLE 1: Average of the absolute value of the acceleration response history for the arbitrarily selected points of the model.

\begin{tabular}{lccc}
\hline Node & FEM & $\begin{array}{c}\text { Average of the absolute value } \\
\text { of the acceleration response } \\
\text { history }\left(\mathrm{m} / \mathrm{s}^{2}\right)\end{array}$ \\
& $\begin{array}{c}\text { Seismic wave } \\
(70 \text { gal })\end{array}$ & $\begin{array}{c}\text { Seismic wave } \\
(400 \text { gal })\end{array}$ \\
\hline 2644 & $\begin{array}{c}\text { With semirigid } \\
\text { joint }\end{array}$ & 0.1265 & 0.7519 \\
2921 & $\begin{array}{r}\text { With semirigid } \\
\text { joint }\end{array}$ & 0.1312 & 0.8654 \\
2920 & $\begin{array}{r}\text { With semirigid } \\
\text { joint }\end{array}$ & 0.1980 & 0.9950 \\
2920 & With rigid joint & 0.2120 & 0.9224 \\
2798 & $\begin{array}{r}\text { With semirigid } \\
\text { joint }\end{array}$ & 0.1265 & 0.7206 \\
2798 & With rigid joint & 0.2096 & 1.0017 \\
\hline
\end{tabular}

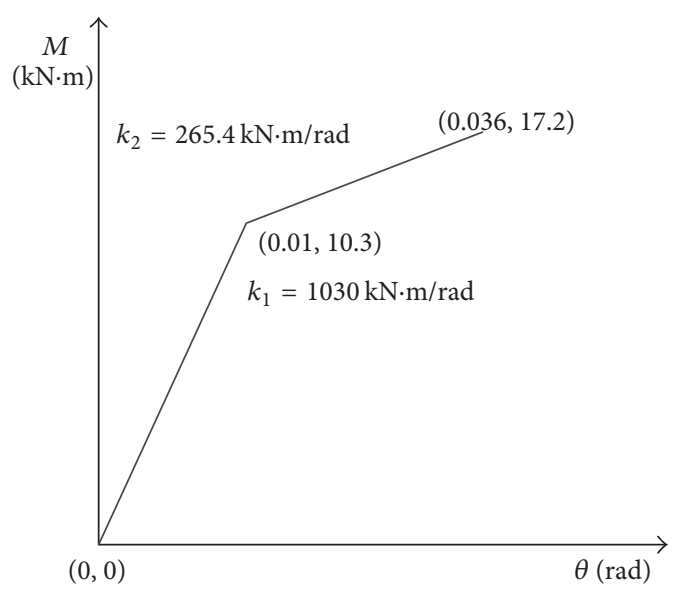

FIGURE 13: Moment-rotation relationship for $k_{\theta y}$.

Node 2644. Results reveal that the semirigid beam-column joints are helpful for seismic resistance of the Tibetan ancient timber structure.

\section{Structural Damage and Rehabilitation Methods}

Most Tibetan ancient timber structures are suffering from different degrees of structural damage which are adverse to the seismic resistance. Typical damage problems of the structural components are summarized below and the main causes of this damage are analyzed. Besides, different rehabilitation methods for maintenance of Tibetan ancient timber structure are discussed.

5.1. Typical Structural Damage. According to the provisions of technical specifications on maintenance and rehabilitation of Chinese ancient timber structure, the following requirements of the structural components should be satisfied [21]:

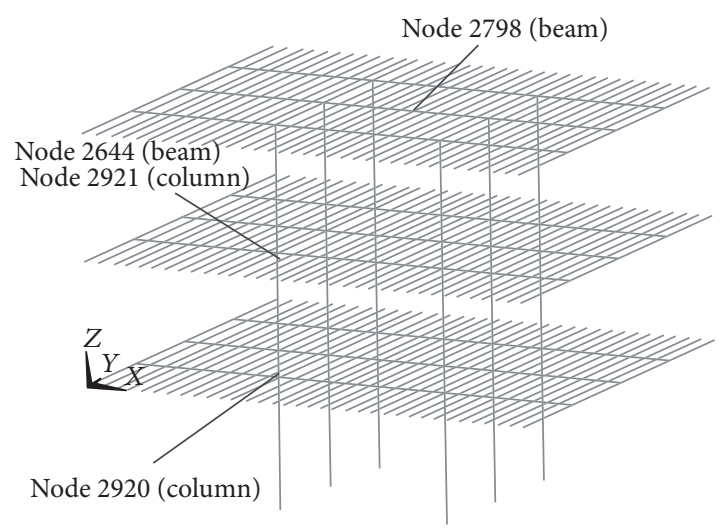

FIGURE 14: Arbitrarily selected points of the model.

(1) Column: material should be in good condition; degrees of cracking and corrosion at the base should be within the allowance.

(2) Mortise and tenon connection: the mortise and tenon should be connected tightly; the extent of pulling out of the tenon from the mortise, cracking, and the crookedness of member should be within the allowance.

(3) Beam: material should be in good condition; excessive deformation or big cracks are not acceptable. The end of beam should be well-connected with other structural components.

(4) Rafter: material should be in good condition; rafters should be firmly connected to the floor slab.

(5) Overall tilt in horizontal direction of the structure should be within the allowance.

Field surveys on structural damage in typical Tibetan ancient timber structures, such as the Patala Palace, Jokhang Temple, and Norbulingka in the city of Lhasa, have been carried out [22]. Approximately one hundred rooms have been surveyed. The typical structural damage is summarized into the following four categories based on these survey results.

(1) Damage of Column. Corrosion of column at the base and crack are the main damage of column, as shown in Figures 16(a) and 16(b). The cross section of the corrupted base would be smaller. When there is an earthquake, the stress in column will substantially increase at the bottom end with possible insufficient axial capacity and large lateral displacement of column.

(2) Damage of Beam. Crack and large deflection are the main damage in beam, as shown in Figures 17(a) and 17(b). Cracks are associated with a smaller cross section of the beam, and thus the sectional stress and deflection of beam increase. 


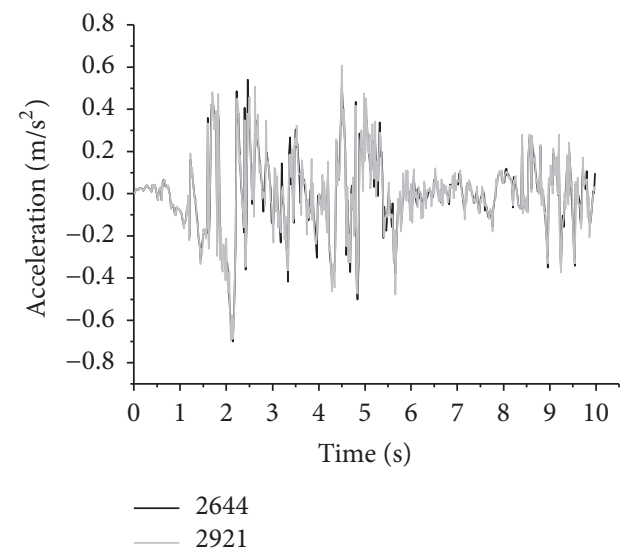

(a) Acceleration responses of Nodes 2644 and 2921 under El-Centro wave with acceleration peak value $70 \mathrm{gal}$

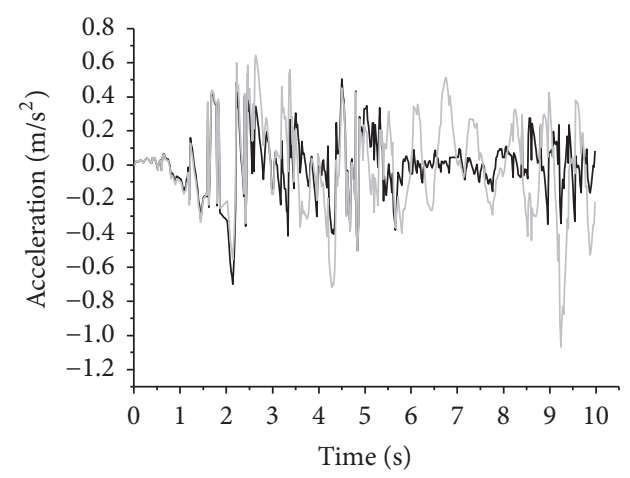

$$
\begin{aligned}
& \text { Node 2798, with semirigid joints } \\
& \text { Node 2798, with rigid joints }
\end{aligned}
$$

(c) Acceleration responses of Node 2798 in the two FEMs under El-Centro wave with acceleration peak value $70 \mathrm{gal}$

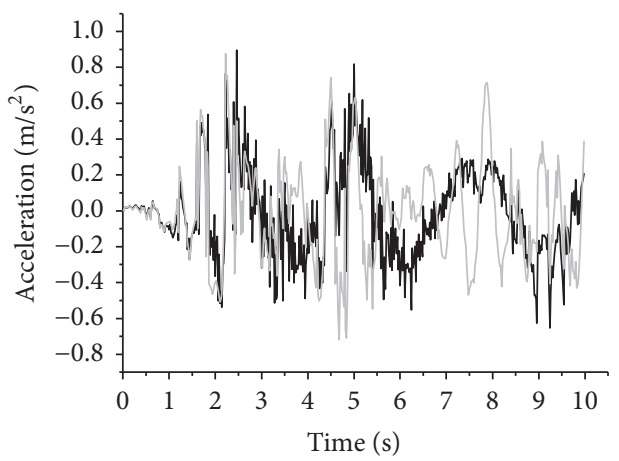

$$
\begin{aligned}
& \text { Node 2920, with semirigid joints } \\
& \text { Node 2920, with rigid joints }
\end{aligned}
$$

(e) Acceleration responses of Node 2920 in the two FEMs under El-Centro wave with acceleration peak value $70 \mathrm{gal}$

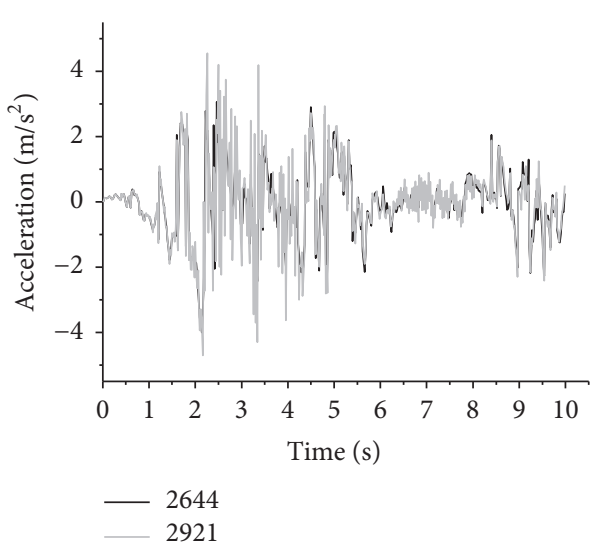

(b) Acceleration responses of Nodes 2644 and 2921 under El-Centro wave with acceleration peak value $400 \mathrm{gal}$

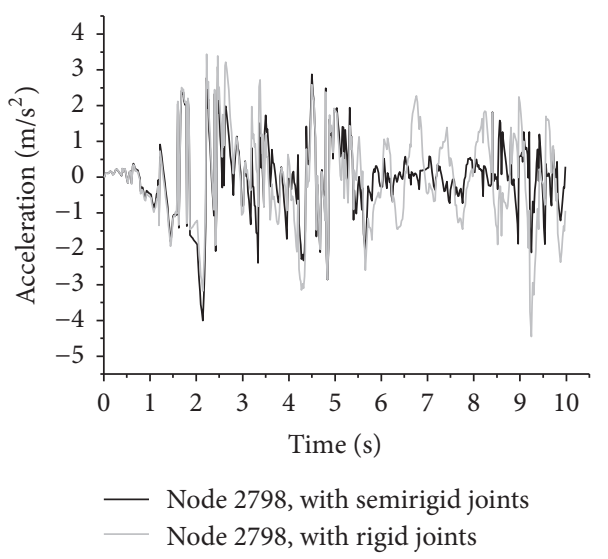

(d) Acceleration responses of Node 2798 in the two FEMs under El-Centro wave with acceleration peak value $400 \mathrm{gal}$

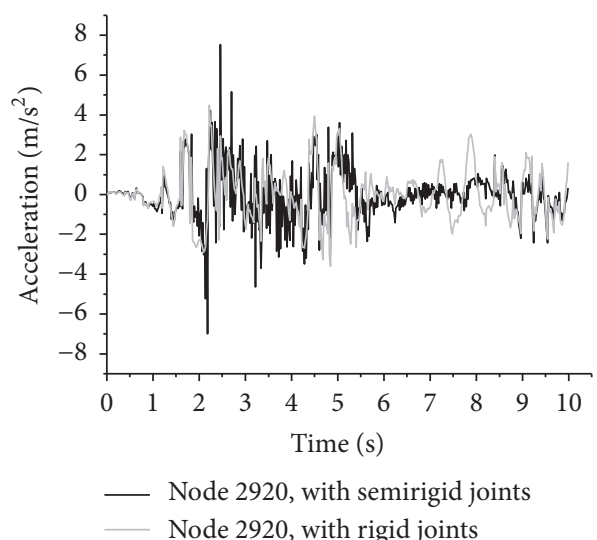

(f) Acceleration responses of Node 2920 in the two FEMs under El-Centro wave with acceleration peak value $400 \mathrm{gal}$

Figure 15: Acceleration responses at the selected points under El-Centro seismic waves. 


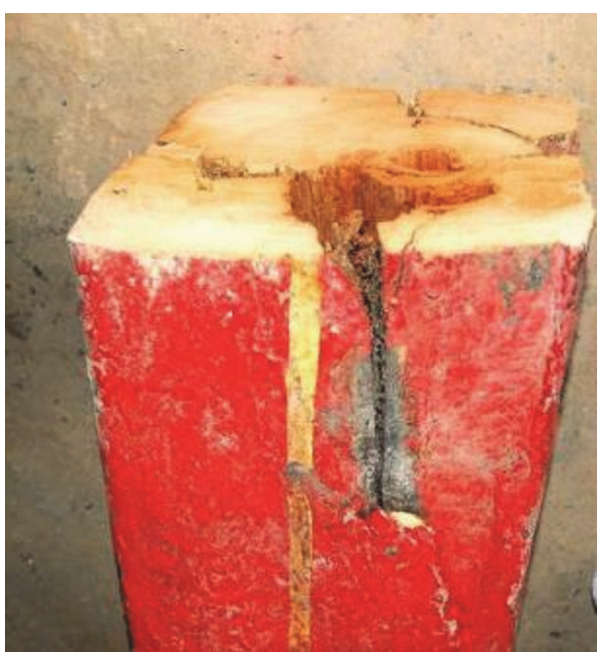

(a) Corrosion of column at the base

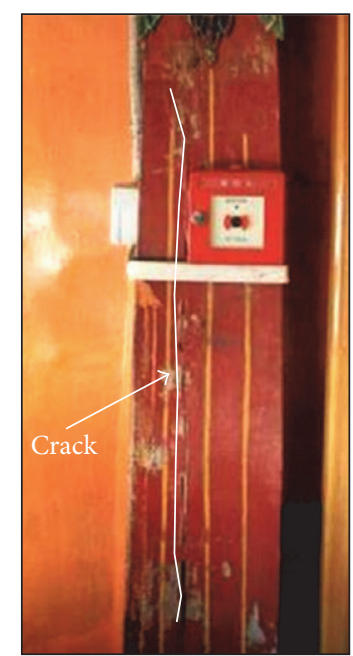

(b) Crack in column

FIgURE 16: Damage of column.

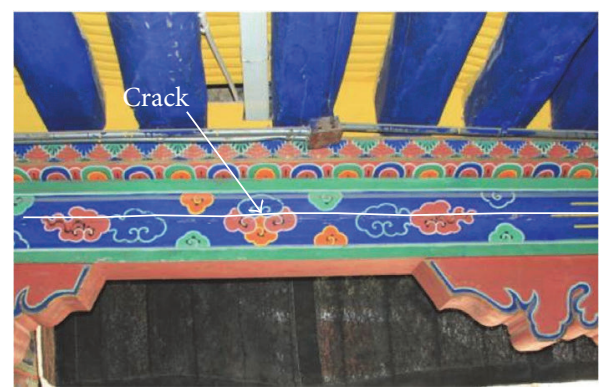

(a) Cracks in beam

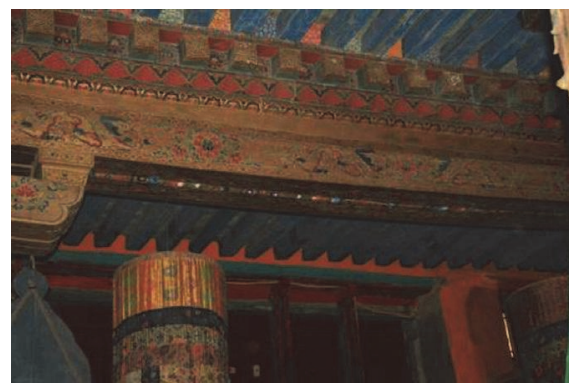

(b) Large deflection

FIGURE 17: Damage of beam.

When earthquake happens, the damaged beams are easier to fail.

(3) Damage in the Cap Block and Chock Block. Radial cracks often exist in the cap blocks as shown in Figure 18(a). Outof-plane distortion is a general type of damage in the chock blocks, as shown in Figure 18(b) that may cause eccentric compression on column and influence the overall stability of the structure.

(4) Damage of Rafter. Crack and corrosion are the main damage in rafter, as shown in Figures 19(a) and 19(b). Cracks accelerate the internal decay of the rafter. Damp and insect induced corruptions make the cross-sections of corrupted rafters become smaller. When earthquake happens, pebbles and stones in the upper floor slab are easier to get loose and fall out.

5.2. Analysis on the Causes of Damage. The damage of structural components is mostly caused by a combination of factors which are summarized into the following categories.

(1) Material Properties. The elastic modulus of timber is low compared to other building materials, and it decreases with time. Under long-term loading, large deformation of structural components may occur, for example, Figure 17(b). Shear strength of timber material is small and shear failure occurs in the structural component, for example, Figures 17(a) and 19(a). Timber is easily corrupted in humid environment, for example, Figure 16(a). Shrinkage of the timber during the drying process will produce cracks, for example, Figures 16(b) and 18(a). In addition, timber is vulnerable to insect effects that may cause damage in the component, for example, Figure 19(b).

(2) Member Arrangement Configuration. Timber frames are pieced together by different components without nails or rivets. Different structure components are connected to each other by short sticks or mortise and tenon connections. The connections need to have open holes which may generate stress concentration causing cracks and additional deformations of the structural components. The distance between adjacent beams and columns is about $1 / 3$ of the height of column, because of the presence of the cap block and chock block. If the upper load distribution is not uniform or the structural components themselves have defects, out-ofplane distortion will happen in the chock blocks, for example, Figure 18(b). 


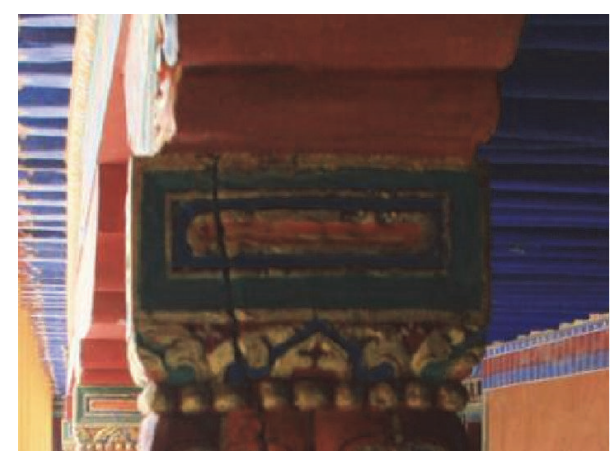

(a) Crack in cap block

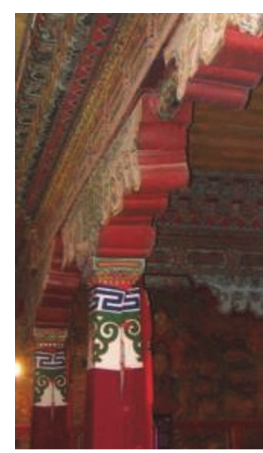

(b) Out-of-plane distortion in the chock blocks

FIGURE 18: Damage of cap block and chock block.

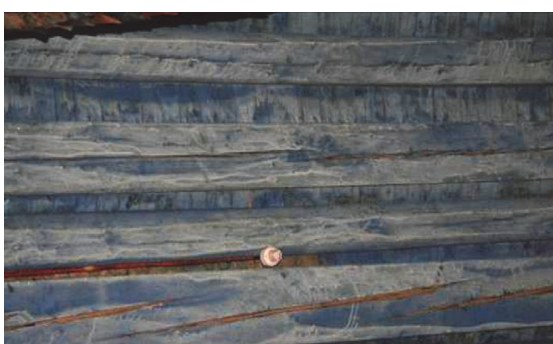

(a) Cracks in rafter

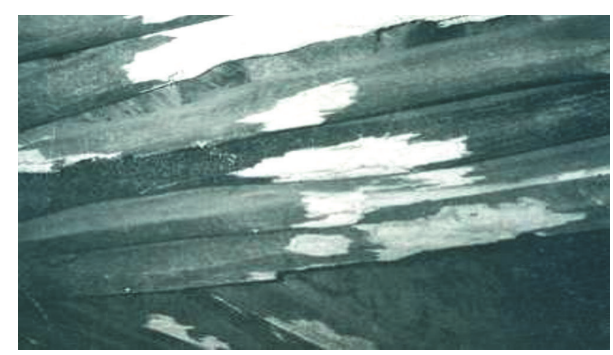

(b) Corrosion

Figure 19: Damage of rafter.

(3) Construction. The base of the column is directly resting on the stone base which is embedded in "Aga" soil forming the floor slab. The column bottom is easily corrupted in the humid environment, for example, Figure 16(a). Similarly, the end of rafter is inserted directly into the wall, and it is also easily corrupted with poor ventilation. For beam-column joint, if the size of the open hole for inserting the short sticks is too large, the joint will have initial deformation after installation and it may induce out-of-plane distortion in the chock blocks, for example, Figure 18(b).

(4) Environment Conditions. Tibet is an earthquake-prone area and yet many Tibetan ancient timber structures remained centuries after their construction. This indicates that they have good seismic performance. However, earthquakes cause damage and deformations of the structures. Wind, rain, and snow also have adverse effects. Humid environment will cause corrosion to the structural components. With the recent development of tourism in Tibet, many ancient buildings are opened to visitors, and the adverse effects of crowd load on the structure will also contribute to the corruption of the structural members.

5.3. Rehabilitation Methods. To ensure the seismic resistance of Tibetan ancient timber structure, some rehabilitation methods are discussed to provide reference for maintenance of the different structural components.
(1) Rehabilitation Methods for Cracks. Traditional metal hoop rehabilitation method can be used for big cracks as shown in Figures 20(a) and 20(b). If the crack is relatively small, wooden bar is used to fill into the crack as shown in Figure 20(c). CFRP which has strong tensile strength can be used to prevent the deformation of the cracked components and to improve the load bearing capacity of the cracked components [23].

(2) Joint Rehabilitation Methods. The rehabilitation of joints in ancient timber structure must satisfy the following requirements [24]: (a) The semirigidity of the joint that can absorb earthquake energy should be maintained; (b) the inner connection between the joint components should be strengthened in order to improve the structural rigidity. Methods using armor plate and CFRP are usually used to reinforce the joints of timber structure [25].

(3) Rehabilitation Method for Beam with Large Deflection. One extra column can be added as an additional support at mid-span of the beam as shown in Figure 21. Internal force redistribution of the beam will take place with the new support. The deflection of beam can be reduced while the bearing capacity of beam can be improved.

(4) Rehabilitation of the Corrupted Components. Conventional method can be used for corrupted column, for example, to replace the corrupted part with new material and 


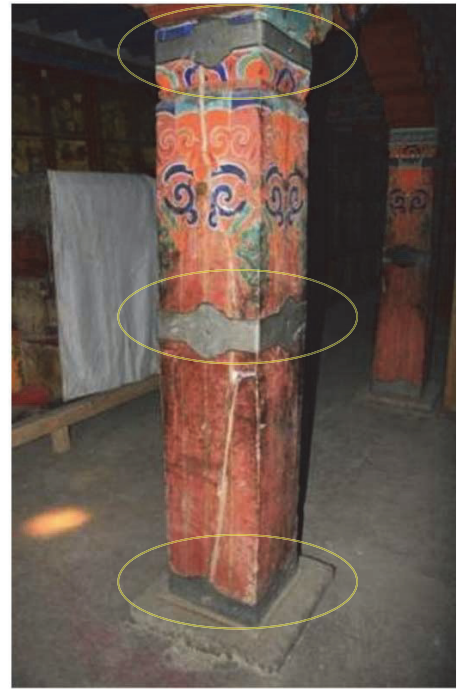

(a) Metal hoop rehabilitation method on column

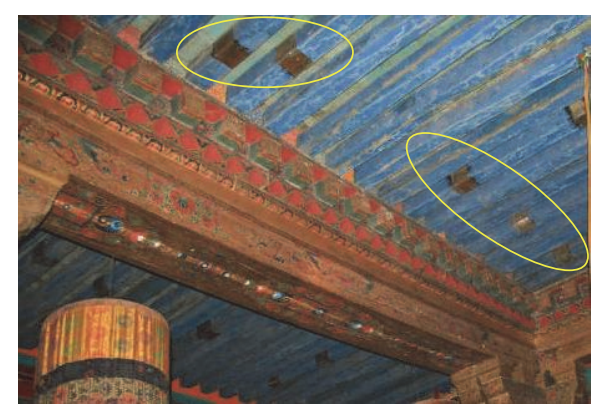

(b) Metal hoop rehabilitation method on rafter

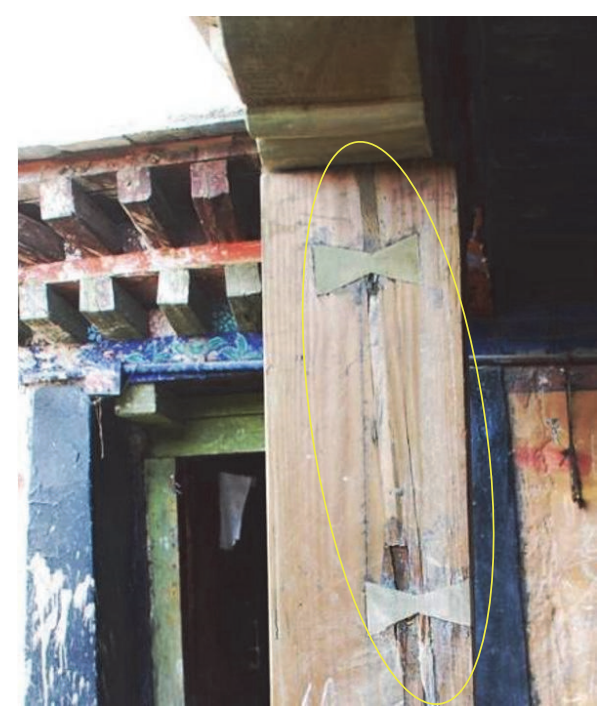

(c) Bar filling method on column

FIGURE 20: Rehabilitation methods for structural components with cracks.

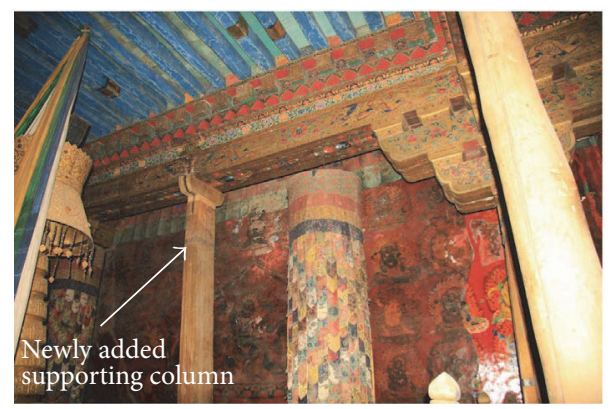

FIGURE 21: Rehabilitation method for beam with large deflection.

use metal hoop to wrap the connection. Glue applied on the corrupted part can be used for reinforcing the corrupted beam. The replacement of corrupted rafters is a little bit complicated as shown in Figures 22(a) and 22(b). The upper floors will have to be removed first. The new rafters replace the old ones, and then the upper floors are put back in position.

\section{Conclusions}

This paper studied the structural configurations of Tibetan ancient timber structure, such as wall, roof and slab, and timber skeleton with semirigid joints. It is found that these construction characteristics enhance the seismic resistance of Tibetan ancient timber structure. One of the unique features of Tibetan ancient timber structure is its special beam-column joint which has a semirigid behavior. Numerical simulations of a typical 3-storey structural unit in the Potala Palace are studied. The acceleration responses at some arbitrarily selected points of the structure under the action of N-S El-Centro seismic waves are studied. Peak acceleration responses of the structure model with semirigid joints are much lower than those from the model with rigid joints. The joints work like dampers which can reduce the earthquake responses by friction and extension of members. Results reveal that the semirigid joint is helpful for seismic resistance of Tibetan ancient timber structure. This paper also summarizes the structural damage which is adverse for seismic resistance. They are mainly categorized into problems with the material properties, member arrangement configuration, construction, and environment conditions. Different rehabilitation methods of structural components are discussed providing references for maintenance of the Tibetan ancient timber structure.

\section{Competing Interests}

The authors declare that there is no conflict of interests regarding the publication of this paper.

\section{Acknowledgments}

This work is supported by the National Natural Science Foundation of China (nos. 51408038 and 51338001) and the 


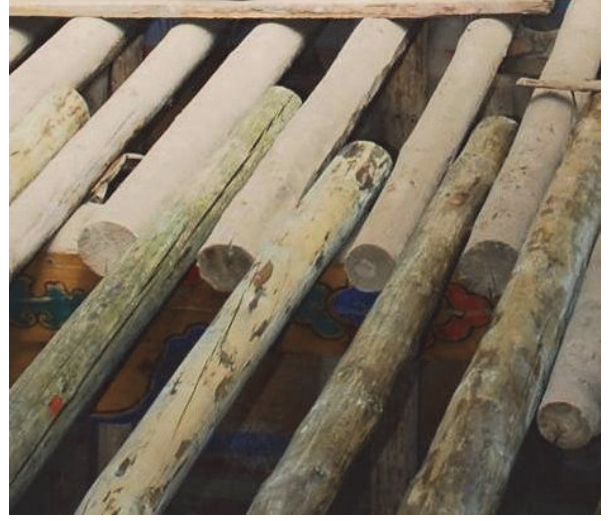

(a) New rafters

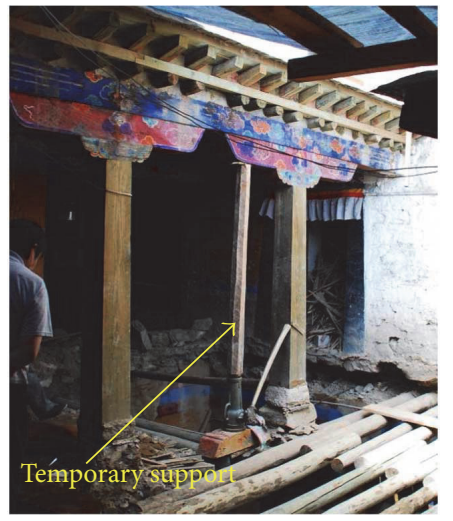

(b) Floor removing

FIGURE 22: Rehabilitation of corrupted rafters.

Talent Fund of Beijing Jiaotong University (no. 2014RC011). The authors would also like to thank the research project funding of the 111 Project of China (no. B13002), the National Key Technology R\&D Program (no. 2015BAK01B02), and the Beijing Natural Science Foundation (no. 8151003).

\section{References}

[1] S. C. Liang, A Pictorical History of Chinese Architecture, MIT Press, Cambridge, Mass, USA, 1984.

[2] B. J. Ma, Wood Construction Techniques of Chinese Ancient Architecture, Science Press, Beijing, China, 1991.

[3] T. Wang, Static Mechanics of Ancient Timber Structures, Historical Relic Press, Beijing, China, 1992.

[4] M. H. Yu, Y. Oda, and D. P. Fang, "Advances in structural mechanics of Chinese ancient architectures," Advances in Mechanics, vol. 36, no. 1, pp. 43-64, 2006.

[5] D. P. Fang, S. Iwasaki, M. H. Yu, Q. P. Shen, Y. Miyamoto, and H. Hikosaka, "Ancient Chinese timber architecture. II: dynamic characteristics," Journal of Structural Engineering, vol. 127, no. 11, pp. 1358-1363, 2001.

[6] J. Y. Xue, P. C. Zhang, and H. T. Zhao, "Study on the aseismic mechanism of historic timber structural building," Journal of Xian University of Architecture \& Technology, vol. 32, no. 1, pp. $8-11,2000$.

[7] P. C. Zhang, Study on structure and its seismic behavior development of Chinese ancient timber structure buildings [Ph.D. thesis], Xian University of Architecture \& Technology, Xian, China, 2003.

[8] L. Sui, Study on aseismic mechanics and analysis on Tou-Kung of Chinese ancient buildings [M.S. thesis], Xian University of Architecture \& Technology, Xian, China, 2006.

[9] K. Yao, H.-T. Zhao, and H.-P. Ge, "Experimental studies on the characteristic of mortise-tenon joint in historic timber buildings," Engineering Mechanics, vol. 23, no. 10, pp. 168-173, 2006.

[10] S. D. Xue, J. Zhao, and X. Y. Gao, Seismic Design of Building, Science Press, Beijing, China, 2007.

[11] H. Y. Jiang and P. Gasu, Potala(Lhasa, China)-Conservation and Restoration, Cultural Relics Publishing House, Beijing, China, 1994.
[12] Y. D. Chen, Tibetan Architecture in China, China Architecture \& Building Press, Beijing, China, 2007.

[13] T. Guo and N. Yang, "Dynamic crowd loading test on Tibetan ancient structures," in Proceedings of the 4th International Symposium on Environment Vibrations-Prediction, Monitoring, Mitigation and Evaluation, pp. 591-598, Beijing Jiaotong University, Beijing, China, October 2009.

[14] H. C. Yan, Experimental research and finite element analysis of timber beam-column connection of Tibetan ancient architecture [M.S. thesis], Beijing Jiaotong University, Beijing, China, 2011.

[15] N. Yang, P. Li, S. S. Law, and Q. Yang, "Experimental research on mechanical properties of timber in ancient tibetan building," Journal of Materials in Civil Engineering, vol. 24, no. 6, pp. 635643, 2012.

[16] G. X. Pan, A History of Chinese Architecture, China Architecture \& Building Press, Beijing, China, 2015.

[17] The Institute for the History of Natural Sciences and Chinese Academy of Sciences, History of Chinese Ancient Architecture Technology, Science Press, Beijing, China, 2000.

[18] A. W. Luo Dan, C. Duo, and P. Ci, Overview of Tibetan Architecture in Tibet, Sichuan Publishing Group, Chengdu, China, 2007.

[19] D. P. Fang, S. Iwasaki, M. H. Yu, Q. P. Shen, Y. Miyamoto, and H. Hikosaka, "Ancient Chinese timber architecture. I: Experimental Study," Journal of Structural Engineering, vol. 127, no. 11, pp. 1348-1357, 2001.

[20] S. Cang, R. X. Zhu, C. X. Ren, and M. H. Yu, "Dynamic analysis of ancient wood structures with mortise and tenon connection," Journal of Ningbo University (NSEE), vol. 17, no. 3, pp. 332-335, 2004.

[21] GB50165-92, "Technical code for maintenance and strengthening of ancient timber buildings," Tech. Rep., 1992.

[22] P. Li, Mechanical mechanism of beam-column joints in wooden frame of tibetan ancient architecture [M.S. thesis], Beijing Jiaotong University, Beijing, China, 2009.

[23] Q. Xu and L. Zhu, "An experimental study on partially-damaged wood columns repaired and strengthened with CFRP," Journal of China Civil Engineering, vol. 40, no. 8, pp. 41-46, 2007.

[24] Q. Zhou, W. M. Yan, and J. B. Ji, “Typical aseismic construction problems in ancient Chinese wooden buildings of the Ming and Qing Dynasties," Science of Conservation and Archaeology, vol. 23, no. 2, pp. 36-48, 2011. 
[25] Q. Xie, H. Zhao, J. Xue, K. Yao, and Y. Sui, "An experimental study on the strengthening of mortise-tenon joints in ancient Chinese wooden buildings," China Civil Engineering Journal, vol. 41, no. 1, pp. 28-34, 2008. 

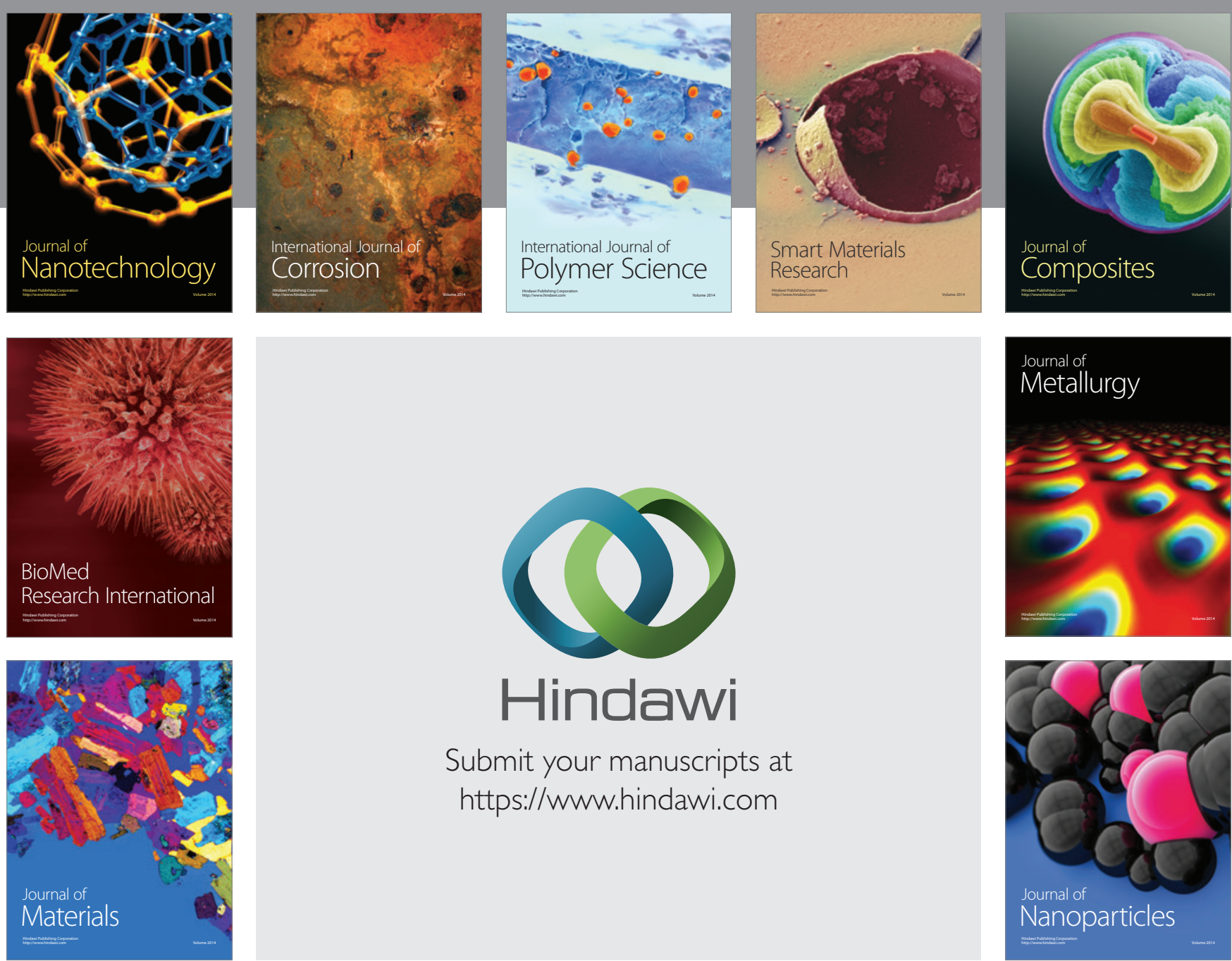

\section{Hindawi}

Submit your manuscripts at

https://www.hindawi.com

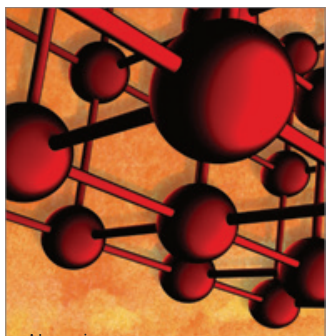

Materials Science and Engineering
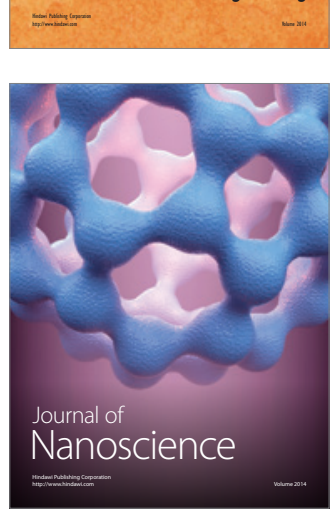
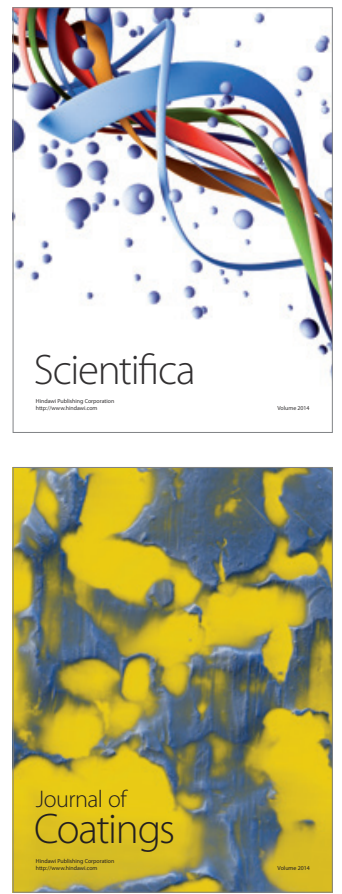
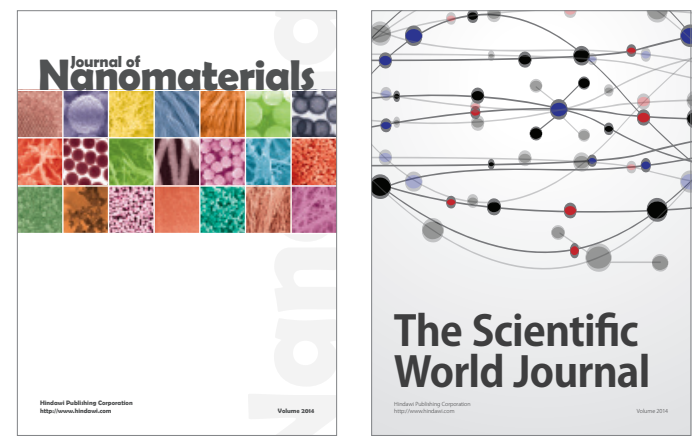

The Scientific World Journal
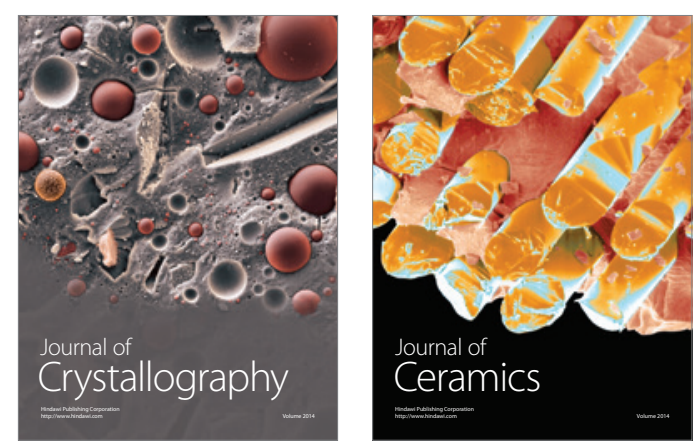
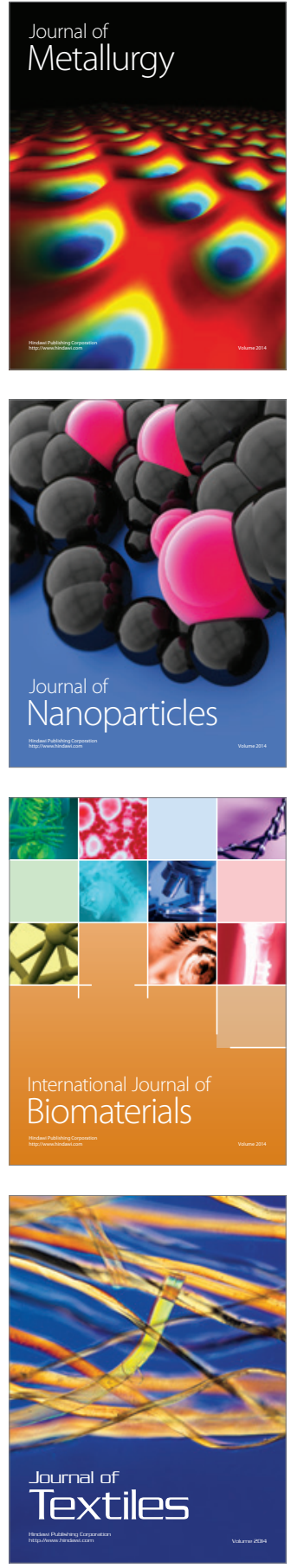